\title{
THE RELATIONSHIP BETWEEN VASCULAR ENDOTHELIAL GROWTH FACTOR-A SERUM LEVEL AND THE SEVERITY OF DIABETIC PERIPHERAL NEUROPATHY
}

Talaat Abdelfatah Abdelaty, Mai Hesham Mohammed Badrah, Salma Alaa Eldin Mostafa Imbaby,* Yousra Hisham Abdel Fattah,** Walid Mohamed Silim

Department of Internal Medicine, Clinical and Chemical Pathology,* Physical Medicine, Rheumatology and Rehabilitation,*** Faculty of Medicine, Alexandria University

\section{Introduction}

Diabetes mellitus causes a broad array of neuropathic complications affecting the peripheral nerves at different locations from the root to the distal axon. It involves sensory, motor and autonomic nerves. Distal symmetric polyneuropathy is recognized as the most common form with pain reported as the chief symptom. So far, tight glycemic control is the only approved treatment that halts progression of neuropathy.

The mechanism of nerve injury in diabetes mellitus is believed to be accounted for by multiple factors including metabolic aberrations and vascular compromise. Increase in polyol flux, accumulation of advanced glycation end-products, oxidative stress and activation of protein kinase $\mathrm{C}$ are thought to be the key drivers in the pathophysiology of neuropathy. Recent studies have attempted to study the role of depletion of neurotrophic factors such as VEGF in the development of diabetic peripheral neuropathy (DPN). Study of these pathophysiologic changes is vital in the quest to find treatment.

Vascular endothelial growth factor (VEGF) is a potent cytokine for endothelial cells and is usually released in response to hypoxia. It promotes angiogenesis and development of collateral vessels in tissues undergoing ischemic changes. It has been strongly implicated in the development of diabetic retinopathy and has been associated with glomerular changes in diabetic nephropathy. Very little information is available with glomerular changes in diabetic nephropathy. Very little information is available
regarding the role of VEGF in diabetic neuropathy. Studies have shown that it can be both a pathogenic factor and also a protective factor in diabetic neuropathy.

\section{Aim of the work}

The aim of the present study was to demonstrate the relationship between serum VEGF-A levels and the severity of DPN.

\section{Subjects and Methods}

A cross-sectional study was conducted on 81 patients with diabetes mellitus. All participants were subjected to full history and physical examination. Electromyography was used to diagnose and stage neuropathy. 14 patients had no neuropathy, 24 had mild neuropathy, 33 had moderate neuropathy and 10 patients measured Additionally, glycemic control, blood pressure, total cholesterol and BMI were some recorded parameters.

\section{Results}

\begin{tabular}{|c|c|c|c|c|c|c|}
\hline & \multirow{2}{*}{$\mathbf{N}$} & \multicolumn{3}{|c|}{ VEGFR } & \multirow{2}{*}{$\begin{array}{c}\text { Test of } \\
\text { Sig. }\end{array}$} & \multirow{2}{*}{$\mathbf{p}$} \\
\hline & & Min. - Max. & Mean \pm SD. & Median & & \\
\hline \multicolumn{5}{|l|}{ Electrophysiologic score } & \multirow{3}{*}{$\begin{array}{c}\mathrm{t}= \\
1.836\end{array}$} & \multirow{3}{*}{0.070} \\
\hline Normal & 14 & $104.20-333.20$ & $247.94 \pm 60.47$ & 248.15 & & \\
\hline With neuropathy & 67 & $107.20-336.10$ & $219.42 \pm 51.22$ & 222.60 & & \\
\hline Normal & 14 & $104.20-333.20$ & $247.94^{\mathrm{a}} \pm 60.47$ & 248.15 & \multirow{4}{*}{$\begin{array}{c}\mathrm{F}= \\
18.438^{*}\end{array}$} & \multirow{4}{*}{$<0.001$} \\
\hline Mild & 24 & $166.10-336.10$ & $250.38^{a} \pm 45.78$ & 238.65 & & \\
\hline Moderate & 33 & $161.20-288.70$ & $221.10^{\mathrm{a}} \pm 32.66$ & 222.60 & & \\
\hline Severe & 10 & $107.20-178.70$ & $139.61^{b} \pm 21.19$ & 139.50 & & \\
\hline \multicolumn{5}{|l|}{ Combined score } & \multirow{3}{*}{$\begin{array}{c}\mathrm{t}= \\
1.254\end{array}$} & \multirow{3}{*}{0.214} \\
\hline Normal & 13 & $104.20-326.60$ & $241.38 \pm 57.52$ & 245.30 & & \\
\hline With neuropathy & 68 & $107.20-336.10$ & $221.10 \pm 52.68$ & 222.60 & & \\
\hline Normal & 13 & $104.20-326.60$ & $241.38^{\mathrm{a}} \pm 57.52$ & 245.30 & \multirow{3}{*}{$\begin{array}{c}\mathrm{F}= \\
10.443\end{array}$} & \multirow{3}{*}{$<0.001^{*}$} \\
\hline Subclinical & 30 & $166.10-336.10$ & $249.76^{\mathrm{a}} \pm 47.71$ & 246.25 & & \\
\hline Confirmed & 38 & $107.20-288.70$ & $198.47^{b} \pm 45.26$ & 210.20 & & \\
\hline \multicolumn{5}{|l|}{ Coronto score } & \multirow{5}{*}{$\begin{array}{c}\mathrm{F}= \\
6.938^{*}\end{array}$} & \multirow{5}{*}{$<0.001^{*}$} \\
\hline Normal $(0-5)$ & 46 & $104.20-336.10$ & $243.56 \pm 51.10$ & 241.05 & & \\
\hline Mild (6-8) & 17 & $136.70-288.70$ & $212.60 \pm 42.0$ & 215.90 & & \\
\hline Moderate $(9-11)$ & 12 & $107.20-262.30$ & $196.43 \pm 46.01$ & 202.10 & & \\
\hline Severe $(12-19)$ & 6 & $115.90-238.70$ & $166.20 \pm 49.27$ & 155.85 & & \\
\hline \multicolumn{5}{|l|}{ VPT } & \multirow{3}{*}{$\begin{array}{c}t= \\
3.916\end{array}$} & \multirow{3}{*}{$<0.001^{*}$} \\
\hline$<25$ (no neuropathy) & 60 & $104.20-336.10$ & $237.07 \pm 49.41$ & 236.30 & & \\
\hline$\geq 25$ (with neuropathy) & 21 & $107.20-266.10$ & $188.02 \pm 49.32$ & 203.60 & & \\
\hline
\end{tabular}

Table 2: Correlation between VEGF and laboratory investigations $(\mathrm{n}=81)$.

\begin{tabular}{|l|c|c|}
\hline & \multicolumn{2}{|c|}{ VEGFR } \\
\hline & $\mathbf{r}_{\mathrm{s}}$ & $\mathbf{p}$ \\
\hline HbA1c & -0.417 & $<0.001^{*}$ \\
\hline Creatinine & -0.391 & $<0.001^{*}$ \\
\hline Total Cholesterol & -0.278 & $0.012^{*}$ \\
\hline
\end{tabular}

r:
*: Spearman coefficient
Statistically significant at $\mathrm{p} \leq 0.05$

\section{Conclusion}

- From the results of the present study, we can conclude that there was significant negative correlation between levels of VEGF-A and the degree of diabetic neuropathy. Additionally, we found significantly low levels of VEGF-A in patients with advanced neuropathy.

- Furthermore, negative correlations were observed between serum VEGF-A and the following parameters: glycemic control, total cholesterol and serum creatinine.

2021OAlexandria Faculty of Medicine
CC-BY-NC

